\title{
Espécies de cigarrinhas (Hemiptera, Cicadellidae, Cicadellinae) em pomares de citros da região de Bebedouro, SP, com descrição de uma espécie nova de Acrogonia Stål
}

\author{
Rosangela Cristina Marucci ${ }^{1}$ \\ Rodney Ramiro Cavichioli ${ }^{2}$ \\ Roberto Antonio Zucchi ${ }^{1}$
}

\begin{abstract}
Aвstract. Sharpshooter leafhoppers (Hemiptera, Cicadellidae, Cicadellinae) in citrus groves of the area of Bebedouro, SP, with description of a new species of Acrogonia Stål. Sixteen species of Cicadellidae, subfamily Cicadellinae, were collected and identified: 11 of the tribe Cicadellini and five of the tribe Proconiini. The ten most common species, together with a new species, are characterized based on external morphology and male genitalia: Acrogonia citrina Marucci \& Cavichioli sp. nov.; Bucephalogonia xanthophis (Berg, 1879); Dilobopterus costalimai Young, 1977; Ferrariana trivittata (Signoret, 1854); Hortensia similis (Walker, 1851); Macugonalia cavifrons (Stål, 1862); M. leucomelas (Walker, 1851); Oncometopia facialis (Signoret, 1854); Plesiommata corniculata Young, 1977 and P. mollicella (Fowler, 1900). The leafhopper samples were collected in citrus groves and in adjacent habitats (woods, swamp, cultivable plain, spontaneous vegetation of the grove, coffee crop and sugarcane) at the counties of Bebedouro and Monte Azul Paulista and in the district of Turvínia. The collecting methods were: insect net, yellow sticky cards, portable suction trap and Malaise trap. Identification keys were elaborated for the 16 species. There is a great diversity of Cicadellinae species in the citric groves. In the three areas sampled, it was collected a larger number of species of the tribe Cicadellini than of the tribe Proconiini. In the Bebedouro area, the vector species of Xylella fastidiosa, A. citrina sp. nov., B. xanthophis, D. costalimai and $O$. facialis, were collected in the citrus groves and in all adjacent habitats.
\end{abstract}

Keywords. Cicadellinae; Cicadellini; identification keys; Proconiini; vector.

\section{INTRODUÇÃO}

No Brasil, na cultura dos citros, ocorrem mais de 70 espécies de cigarrinhas pertencentes a oito famílias, que podem ser observadas tanto nas plantas cítricas, como na vegetação espontânea do pomar (PAIVA et al. 1996). Entre as famílias de Auchenorrhyncha que ocorrem em citros, Cicadellidae é a mais numerosa, com 11 subfamílias e mais de 55 espécies (Yамамото \& GRAVENA 2000).

As subfamílias Cicadellinae e Deltocephalinae têm maior representatividade, embora existam poucos trabalhos disponíveis na literatura (CAVICHIOLI \& ZANOL 1991).

A subfamília Cicadellinae compreende duas tribos (Young 1968): Proconiini e Cicadellini. A primeira, contendo os maiores cicadelíneos, está restrita ao hemisfério ocidental (Young 1968) e possui atualmente 56 gêneros e aproximadamente 350 espécies válidas. A segunda, com maior número de espécies (cerca de
1.100), ocorre em todas as regiões zoogeográficas (NIELSON 1985), sendo a Região Neotropical a mais rica em espécies (Osborn 1926; MetCalf 1965; Young 1977). No Novo Mundo, Cicadellini possui atualmente 237 gêneros e cerca de 500 espécies válidas.

Os Cicadellinae constituem um grupo grande e diversificado, sendo assim difícil caracterizá-los (Young 1968). Os caracteres que definem Proconiini e Cicadellini apresentam poucas variações nos diversos gêneros. Em Proconiini, os gêneros e os grupos de gêneros são bem definidos, enquanto em Cicadellini há problemas na caracterização dessas categorias (Young 1968, 1977 e 1986).

Todos os membros da subfamília Cicadellinae alimentamse do xilema sem danificá-lo, indicando não somente uma correlação entre uma função biológica e morfológica, mas também uma base biológica para identificação e separação da subfamília (NIELSON 1985).

\footnotetext{
1. Departamento de Entomologia, Fitopatologia e Zoologia Agrícola, Escola Superior de Agricultura "Luiz de Queiroz". Caixa Postal 09, 13.418-900 Piracicaba-SP, Brasil. Endereço eletrônico: rcmarucc@carpa.ciagri.usp.bre razucchi@carpa.ciagri.usp.br

2. Departamento de Zoologia, Universidade Federal do Paraná. Caixa Postal 19020, 81531-980 Curitiba-PR.

Endereço eletrônico: cavich@garoupa.bio.ufpr.br
} 
A capacidade de transmissão de doenças pelas cigarrinhas da subfamília Cicadellinae está relacionada ao fato desses insetos se alimentarem única e exclusivamente no xilema. Portanto, apresentam a musculatura da cabeça bastante desenvolvida para sucção da seiva, que circula sob pressão negativa na planta (Young 1968; NIELSON 1985; WILSON \& Claridge 1991). Essas cigarrinhas são dotadas de fronte bem desenvolvida, seguida ventralmente por um aparelho bucal com múltiplos músculos, necessários para retirar a seiva do xilema.

Poucas cigarrinhas se especializaram evolutivamente em se alimentar no xilema e, provavelmente, essas sejam as mais eficientes em transmitir Xylella fastidiosa de uma planta para outra (FRAZIER 1944; PAIVA et al. 1996). Em citros, esta bactéria é o agente causal da Clorose Variegada dos Citros (CVC), doença amplamente dispersa no norte e nordeste do estado de São Paulo.

Levantamentos populacionais e observações de campo, associados aos estudos de transmissão de $X$. fastidiosa por cigarrinhas em citros, identificaram cinco espécies como vetores: Dilobopterus costalimai Young, Oncometopia facialis (Signoret), Acrogonia terminalis Young (sensu LoPes et al. 1996; RoBerTo et al. 1996), Bucephalogonia xanthophis (Berg) e Plesiommata corniculata Young (KRÜGNER et al. 1998). Foram divulgados recentemente seis novos registros de espécies vetoras de $X$. fastidiosa em citros: Acrogonia virescens (Metcalf), Homalodisca ignorata Melichar (Yамамото et al. 2000), Ferrariana trivittata (Signoret), Macugonalia leucomelas (Walker), Parathona gratiosa (Blanchard) e Sonesimia grossa (Signoret) (FundECITRUs 1999).

A identificação de cigarrinhas é baseada inteiramente em caracteres morfológicos, especificamente da genitália do macho. Dados de plantas hospedeiras, comportamento, preferências ecológicas e outros conhecimentos de biologia têm sido importantes para caracterizar as espécies, mas esses critérios não têm base para a identificação (NIELSON 1985). Por serem vetoras de patógenos, a compreensão da posição específica e inter-relações genéticas entre populações tornam-se importantes (CLARIDGE 1985).

A rápida dispersão de CVC no Brasil sugere que a bactéria é facilmente transmitida por insetos vetores (LOPES 1996), embora a eficiência de transmissão de $X$. fastidiosa pelas cigarrinhas, em geral seja baixa. As cigarrinhas da Tribo Cicadellini parecem ser mais eficientes do que as da Tribo Proconiini (R. KRÜGNER, comunicação pessoal).

Este trabalho teve por objetivos identificar e caracterizar as espécies de cigarrinhas da subfamília Cicadellinae mais comuns em pomares cítricos da região de Bebedouro (SP) e descrever uma espécie nova de Acrogonia Stål, 1869, A. citrina sp. nov.

\section{MATERIAL E MÉTODOS}

As coletas de cigarrinhas foram efetuadas na região de Bebedouro (SP), incluindo os municípios de Bebedouro e Monte Azul Paulista e o distrito de Turvínia, em pomares com 4 e 8 anos de idade, com histórico de alta população de cigarrinhas. Amostraram-se não somente as plantas cítricas (1.200 plantas de laranja 'Natal' e 3.000 plantas de laranja 'Hamlin'), mas também habitats adjacentes variados: floresta hidrofólia, floresta estacional semi-decidual degradada, floresta estacional semi-decidual aluvial, cerrado, brejo, vegetação espontânea do pomar, capim-braquiária (Brachiaria decumbens Stapf) e culturas próximas (cafeeiros e cana-de-açúcar).

Os métodos utilizados nas amostragens quinzenais foram: rede entomológica (4 batidas/quadrante/planta, em 50 plantas), cartões retangulares amarelos $(7,5 \times 12 \mathrm{~cm})$ contendo cola (Olson Products $\left.{ }^{\circledR}\right)$, succionador motorizado (20 plantas) e armadilhas de Malaise ( 6 X 2 X 2,5 m) contendo dois frascos de coleta com inseticida Diclorvos (Revenge $®)$ ).

Para o estudo da genitália dos machos, foi adotada a técnica descrita por OMAN (1949) com algumas modificações. Para o estudo da venação das asas, estas foram retiradas do exemplar e colocadas sobre lâminas contendo glicerina e posteriormente colocada uma lamínula sobre a asa. Depois de desenhada, a asa foi retirada da lâmina e colocada junto ao inseto em um triângulo de cartolina fixado no alfinete de montagem. As medidas do comprimento dos machos e fêmeas estão expressas em milímetros; foram medidos 20 exemplares (10 machos e 10 fêmeas) de cada espécie de cigarrinha caracterizada, sendo apresentados a média de cada conjunto de dez, e seu desvio padrão.

Os exemplares estudados estão depositados nas seguintes instituições: Escola Superior de Agricultura "Luiz de Queiroz"ESALQ/USP, Piracicaba, São Paulo e Departamento de Zoologia da Universidade Federal do Paraná, coleção de Entomologia "Pe. Jesus Santiago Moure" (DZUP), Curitiba, Paraná. Para o trabalho foram examinados exemplares da coleção do DZUP; Museu Nacional, Universidade Federal do Rio de Janeiro (MNRJ) e The Natural History Museum, Londres, Inglaterra (BMNH).

A caracterização de adultos foi feita com base nos caracteres taxonômicos utilizados por Young (1968, 1977 e 1986), Blocker \& Triplehorn (1985), Nielson (1985) E MEJdALANi (1998).

\section{RESULTADOS EDISCUSSÃO}

Nos levantamentos de cigarrinhas, realizados em pomares cítricos da região de Bebedouro, várias espécies pertencentes à família Cicadellidae foram coletadas, no entanto, selecionaramse algumas mais comuns pertencentes à subfamília Cicadellinae. As espécies em que houve dúvidas quanto à identificação, não foram incluídas neste trabalho. Os cicadelíneos selecionados encontram-se listados a seguir:

\section{Tribo Proconiini}

Young (1968) caracteriza esta tribo por apresentar a junção fêmur - tíbia da perna posterior não atingindo a margem posterior do proepimero, quando em repouso; pigóforo e placa subgenital dos machos apresentando numerosas microcerdas, e lóbulos supra-antenais proeminentes. 
1 - Acrogonia citrina sp. nov.

2 - Acrogonia virescens (Metcalf, 1949)

3 - Homalodisca ignorata Melichar, 1924

4 - Oncometopia facialis (Signoret, 1854)

5 - Teletusa limpida (Signoret, 1855)

\section{Tribo Cicadellini}

Young (1968) caracteriza a tribo por apresentar a junção fêmur-tíbia da perna posterior atingindo a margem posterior do proepimero; pigóforo e ou placa subgenital dos machos com macrocerdas, quando ausentes, com microcerdas, porém não dispersas igualmente como nos Proconiini; lóbulos supraantenais não prominentes.

\section{6 - Bucephalogonia xanthophis (Berg, 1879) \\ 7 - Dilobopterus costalimai Young, 1977 \\ 8 - Ferrariana trivittata (Signoret, 1854) \\ 9 - Hortensia similis (Walker, 1851) \\ 10 - Macugonalia cavifrons (Stål, 1862) \\ 11 - Macugonalia leucomelas (Walker, 1851) \\ 12 - Oragua triplehorni Young, 1977 \\ 13 - Parathona gratiosa (Blanchard, 1840) \\ 14 - Plesiommata corniculata Young, 1977 \\ 15- Plesiommata mollicella (Fowler, 1900) \\ 16 - Sonesimia grossa (Signoret, 1854)}

\section{Chave para espécies de Proconiini}

1. Superfície do corpo pubescente ...................................... 2

Superfície do corpo não pubescente

2(1). Pernas anteriores com tíbia expandida e achatada no ápice (Fig. 1A) Teletusa limpida

Pernas anteriores com tíbia normal ou levemente dilatada

3(2). Fronte dilatada, convexa, com granulações entre as impressões musculares de cada lado da fronte e manchas escuras nos lados superior e inferior da cabeça (Fig. 14A). Edeago assimétrico, com uma série de processos dispostos irregularmente (Fig. 14F) Oncometopiafacialis

Fronte levemente achatada medianamente ou deprimida, sem granulações entre as impressões musculares de cada lado da fronte. Edeago simétrico com um par de processos ventrais e a haste curvada dorsalmente (Fig. 2C) Homalodiscaignorata.

4(1). Cabeça, pronoto e escutelo de coloração escura com manchas amarelas (Fig. 7A). Conetivo e estilos delgados (7G). Edeago subcilíndrico com apódemas voltados anteriormente e bífido desde o terço basal (Fig.7H e 7I) ........................ Acrogonia citrina sp.nov.

Cabeça, pronoto e escutelo sem manchas amarelas (Fig. 3A e 3B); coloração dorsal variável; mancha na forma de U no ápice da cabeça. Estilos alongados, curvados internamente e em forma de gancho no ápice. Conetivo em Y (Fig. 3C). Edeago alongado com o ápice fino e pontiagudo; área basal na forma de um Y (Fig. 3D) Acrogonia virescens

\section{Chave para as espécies de Cicadellini}

1. Asas anteriores com máculas ........................................... 2

Asas anteriores sem máculas ............................................. 5

2(1). Asas anteriores com a área maculada opaca, delimitada por uma porção membranosa

Asas anteriores com pequenas máculas pálidas em quase toda a extensão (Fig. 4A) Oragua triplehorni

3(2). Asas anteriores com numerosas máculas pequenas em toda porção da área opaca (Fig. 5A e 12B) .............. 4

Asas anteriores com poucas máculas pequenas e duas manchas largas, distintas e pálidas (Fig. 13B)....

.. Macugonalia leucomelas

4(3). Asas anteriores com numerosas máculas pequenas arranjadas em série, e com uma distinta mancha grande arredondada, situada próxima ao ápice do clavo (Fig. 5A). Cabeça amarelo-alaranjada com algumas linhas pretas; ocelos localizados atrás da linha imaginária que tangencia os ângulos oculares anteriores (Fig. 5B); fronte clara e sem manchas amarelas

Parathona gratiosa

Asas anteriores manchadas em toda área opaca (Fig. 12B), seguindo o mesmo padrão na cabeça e tórax (Fig. 12A). Face com muitas manchas escuras no disco da fronte, e somente uma área central não-manchada ........ Macugonalia cavifrons

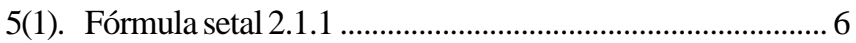

Fórmula setal diferente de 2.1.1 9

6(5). Asas anteriores praticamente hialinas, com veias salientes ou distintas (Fig. 9B e 15B) 7

Asas anteriores não hialinas, com veias distintas ou não

7(6). Asas posteriores com um conspícuo lobo jugal alargado (Fig. 9C) Dilobopterus costalimai

Asas posteriores sem lobo jugal alargado .. 8

8(7). Edeago, em vista lateral, com a haste bastante expandida no ápice (Fig. 15F); em vista ventral, semelhante a uma taça. (Fig. 15E) ............. Plesiommata corniculata

Edeago, em vista lateral, com a haste com uma expansão dorsal de cada lado (Fig. 16C)

Plesiommata mollicella

9(5). Asas anteriores com faixas longitudinais contrastantes 

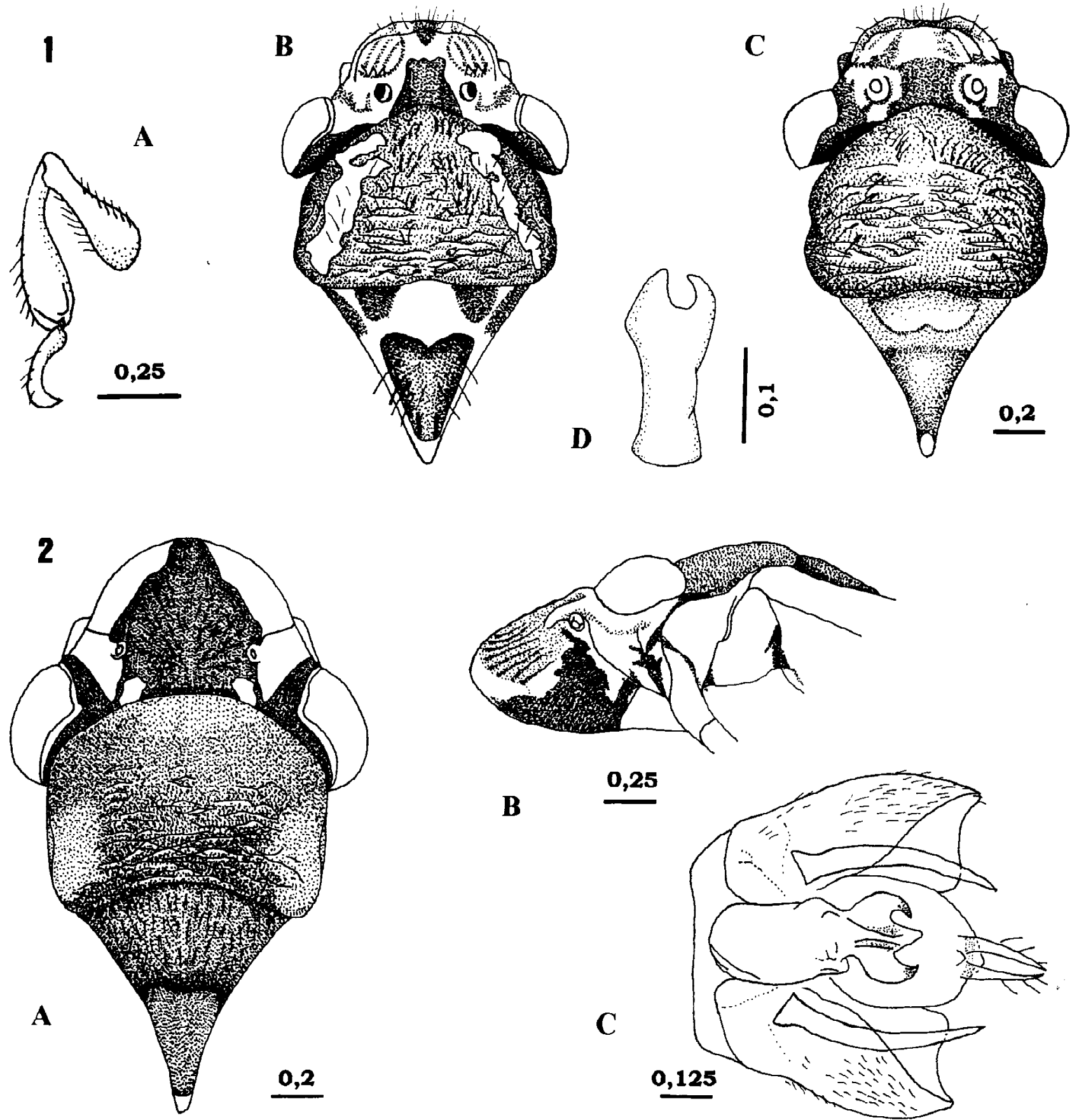

Fig.1. Teletusa limpida (Signoret, 1855): A, fêmur, tíbia e tarso da perna anterior (vista lateral); B e C, cabeça, pronoto e escutelo de fêmea e macho (vista dorsal); D, edeago (vista ventral). Fig. 2. Homalodisca ignorata Melichar, 1924: A e B, cabeça, pronoto e escutelo (vista dorsal e lateral); C, pigóforo e edeago (vista ventral). 
(Fig. 10B). Coroa com uma faixa de cor laranja ou vermelha, próxima à margem anterior (Fig. $10 \mathrm{~A}$ ).... Ferrariana trivittata

Asas anteriores com uma área opaca esverdeada, delimitada por uma membrana, incluindo as células apicais; coroa e porção anterior do pronoto com uma série de manchas lineares escuras (Fig. 11A).

Hortensia similis

10(6). Asas anteriores com o terço apical membranoso, incluindo parcialmente as células anteapicais, veias não elevadas (Fig. 8C). Coloração variando de amarelo a verde, com ou sem conspícuas manchas escuras na coroa (Fig. 8A e 8B) ....... Bucephalogonia xanthophis Asas anteriores opacas com veias claras e salientes. Cabeça, pronoto e escutelo com duas faixas longitudinais pretas, que quase se encontram no ápice da cabeça (Fig. 6A) Sonesimia grossa

Destas, apenas dez espécies mais comuns (duas da tribo Proconiini e oito da tribo Cicadellini, sendo uma nova) foram caracterizadas.

\section{PROCONIINI}

\section{Acrogonia citrina Marucci \& Cavichioli, sp. nov.} (Figs.7A-7I)

Acrogonia terminalis Young, 1968 sensu Lopes et al., 1996:343; Roberto et al., 1996:517.

Acrogonia sp. sensu Marucci et al., 1999: 441; Marucci et al., 2000: 669.

Diagnose. Ápice da cabeça levemente voltado para cima, em vista lateral; superfície dorsal da cabeça, pronoto e escutelo com máculas amarelas e amarelo-esverdeadas; edeago bífido desde o terço basal e suavemente curvado.

Holótipo. Macho. BRASIL. São Paulo: Bebedouro, IV-1997, W. Peiffer col. (DZUP). Parátipos. Mato Grosso: Xavantina, Cachimbo, 1 macho, $12^{\circ} 49^{\prime} \mathrm{S} 51^{\circ} 45^{\prime}$ W, 5 XI 1968, R. Beaver. Gallery forest, U.V. light trap. Roy.Soc./Roy. Geog. Soc., Expedition 1967-69. BM 1970192 (BMNH); Sinop, 1 macho, X 1975, M. Alvarenga leg; Ibidem, 1 macho, X-1976. Goiás: Dianópolis, 1 macho, 11/14-I-1962, J. Bechyné col. (DZUP). São Paulo: Bebedouro, 6 machos e 2 fêmeas; Ibidem, 1 macho e 1 fêmea (ESALQ), 1 macho e 1 fêmea (MNRJ), 4 machos (DZUP); Ibidem, 2 machos, 1 fêmea, XI-1996, W. Peiffer leg, Fundecitrus.(DZUP).

Cabeça. Triangular, alongada, com comprimento mediano 7/8 da largura transocular; ápice levemente curvado para cima; coloração preta, manchada irregularmente com amarelo (Figs. 7A e 7B); fronte convexa e levemente dilatada na base; ocelos localizados mais próximos dos olhos que entre si, e atrás da linha imaginária que tangencia os ângulos oculares anteriores; lóbulos suprantenais salientes em vista dorsal; impressões musculares bastante evidentes; face amarelada com as bordas mais escuras.
Tórax. Largura do pronoto igual à largura transocular; coloração preta, com a porção anterior do pronoto e escutelo manchados de amarelo e o restante de azul-amarelado ou verde. Asas anteriores hialinas, com poucas áreas opacas; veias elevadas ou proeminentes; em posição de repouso, o meron exposto e, nas fêmeas cobrindo o ovipositor (Fig. 7C). Asas posteriores não pubescentes, com a veia $\mathrm{R}_{2+3}$ interrompida (Fig. 7D). Pernas de coloração amarela; pernas posteriores com o basitarso mais longo do que o comprimento dos distais juntos.

Genitália do macho. Pigóforo longo, mais de duas vezes a sua maior largura, em geral, com a margem dorsal dobrada internamente e a posterior truncada; com muitas microcerdas distribuídas em toda a superfície; processos ausentes (Fig. 7E). Placa subgenital quase tão longa quanto o pigóforo, triangular, bipartida no terço apical (Fig. 7F). Estilos delgados, tão longos quanto a placa subgenital, pontiagudos e unciformes. Conetivo delgado, com a metade do comprimento dos estilos e com uma projeção médio-ventral (Fig. 7G). Edeago subcilíndrico, largo basalmente e afilado para o ápice (Fig. $7 \mathrm{H}$ ), bífido desde o terço basal e ápice com ramos divergentes e sobrepostos (Fig. 7I), semelhante ao de Acrogonia gracilis (Osborn, 1926) sensu young, 1968:268, Fig. 257g; base do edeago com apódemas voltados anteriormente.

Comprimento. Machos: 9,77 mm $\pm 0,44$ (9,0-10,0 mm). Fêmeas: 10,25 mm \pm 0,42 (10,0-11,0 mm).

Comentários. A. citrina Marucci \& Cavichioli sp. nov. é similar a A. terminalis Young, 1968 e A. gracilis (Osborn, 1926) no aspecto externo, diferindo na forma da genitália do macho, principalmente a do edeago. A. terminalis apresenta o edeago com apódemas voltados dorsalmente e corpo do edeago longo, delgado e fortemente curvado ventralmente (holótipo). $\operatorname{Em} A$. gracilis, os apódemas são muito curtos e com uma projeção ventrobasal; corpo do edeago não tão fortemente curvado como em $A$. terminalis e não tão suave como em $A$. citrina $\mathbf{s p .}$ nov. As espécies de Acrogonia apresentam grande variação intra-específica, principalmente com relação à coloração geral do corpo e também no aspecto do comprimento da cabeça, vista dorsal e em seu ápice.

Acrogonia não está relacionado com outro gênero (Young, 1968), no entanto, MeJdalani (2000) apresentou uma filogenia dos Proconiini com mero exposto, e propôs o gênero como grupo-irmão dos demais gêneros do grupo Abana, porém, ressalta que este posicionamento é duvidoso.

As espécies de Acrogonia, no aspecto externo são muito semelhantes, dificultando sua identificação, principalmente quando se trata de fêmeas. Talvez uma boa revisão genérica, definindo melhor as espécies, utilizando mais caracteres externos, resolveria este problema.

Observações de campo têm demonstrado que a postura de A. citrina sp. nov., não é endofítica. Os ovos são colocados, lado a lado, na superfície inferior das folhas e cobertos por estrutura esbranquiçada. As fêmeas apresentam duas manchas brancas, convexas e esféricas de brocossomos nas asas anteriores, e com as tíbias das pernas posteriores, onde apresentam a terceira fileira de espinhos bastante 

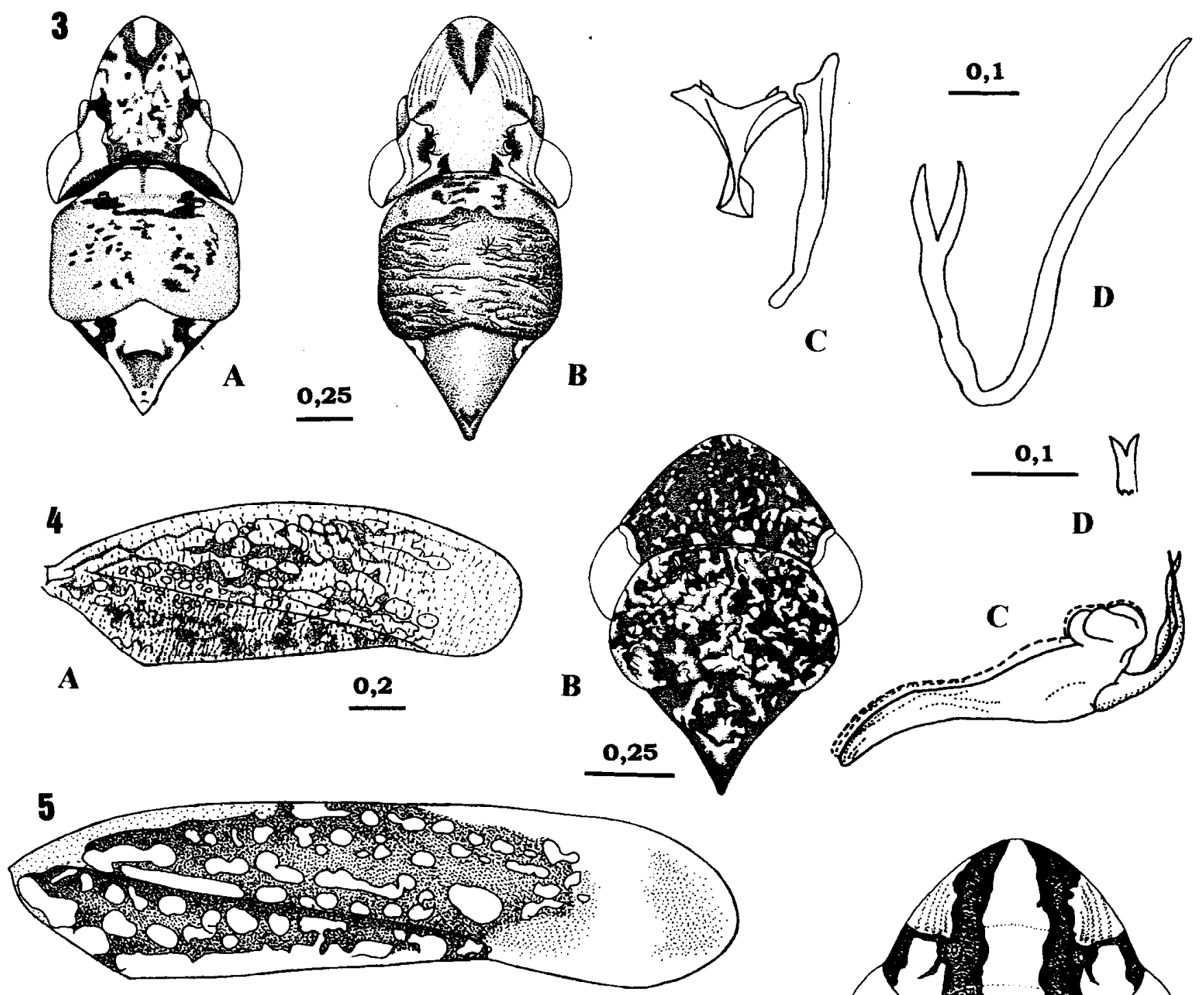

A
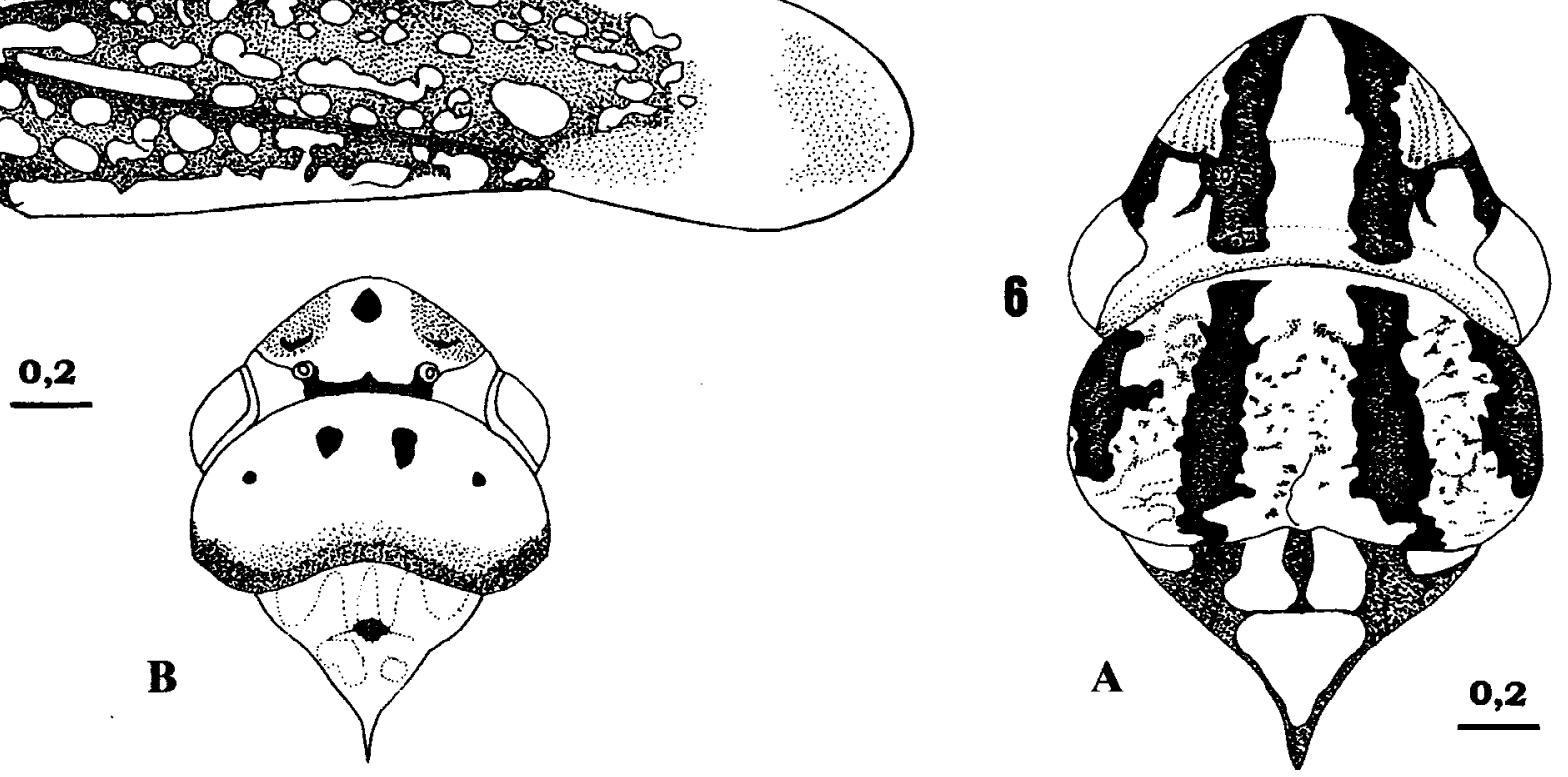

Fig. 3. Acrogonia virescens (Metcalf, 1949): A e B, cabeça, pronoto e escutelo de fêmea e macho (vista dorsal); C, conetivo e estilo (vista dorsal); D, edeago (vista lateral). Fig. 4. Oragua triplehorni Young, 1977: A, asa anterior; B, cabeça, pronoto e escutelo (vista dorsal); C, edeago (vista lateral); D, processos anteapicais do edeago (vista posterior). Fig. 5. Parathona gratiosa (Blanchard, 1840): A, asa anterior; B, cabeça, pronoto e escutelo (vista dorsal). Fig. 6. Sonesimia grossa (Signoret, 1854): A, cabeça, pronoto e escutelo (vista dorsal). 
desenvolvidos, retiram das asas os brocossomos, depositandoos sobre os ovos.

Oncometopia facialis (Signoret, 1854)

(Figs. 14A-14F)

Tettigonia facialis Signoret, 1854:489.

Oncometopia facialis; Young, 1968:227.

Diagnose. Fronte extremamente dilatada, convexa; corpo com coloração arroxeada, com uma série de manchas escuras; edeago assimétrico e com espinhos dipostos irregularmente e esclerotinizados no ápice.

Cabeça mais larga que longa; margem anterior arredondada; coloração marrom-avermelhada, levemente violeta, com uma série de manchas pretas nas porções coroa e face (Fig. 14A); com granulações na região face, de cada lado da fronte, entre as impressões musculares; fronte dilatada, convexa, não achatada medianamente, nem côncava, com a porção mediana mais ou menos larga e escura; ocelos localizados antes da linha imaginária que tangencia os ângulos oculares anteriores, mais próximos aos olhos compostos do que entre si e equidistantes da linha mediana da coroa; lóbulos suprantenais salientes, em vista dorsal; olhos ovalados e salientes.

Tórax marrom-avermelhado levemente violeta; largura do pronoto menor que a largura transocular da cabeça, margem anterior irregularmente escura; disco do pronoto pontuado, rugoso e pubescente; escutelo com uma mancha triangular apicalmente; asas anteriores opacas, com venação distinta, porém com uma área membranosa no ápice (incluindo células apicais e parcialmente células anteapicais) (Fig. 14B); asas posteriores com a veia $R_{2+3}$ incompleta e duas veias cúbito distintas (Fig. 14C); comprimento do basitarso posterior maior que a soma do comprimento dos distais.

Genitália do macho. Pigóforo com processos na margem ventral (Fig. 14D); edeago largo, em vista dorsal, assimétrico, com processos na forma de espinhos dispostos irregularmente e esclerotinizados no ápice, a base em forma de um balão dilatado com um espinho afilado e curvo na porção final restando um ramo com 4 espinhos (Fig. 14F); conetivo em Y, com os braços amplamente divergentes; estilos afastados um do outro, não estendidos além do ápice do conetivo (Fig. 14E); ausência de paráfises.

Comprimento. Machos: 11,0 mm $\pm 0,41(10,5-11,5 \mathrm{~mm})$. Fêmeas: 11,65 mm 0,41(11,0-12,0 mm).

Comentários. O gênero Oncometopia juntamente com Dichropheps Stål, Egidemia China, Homalodisca Stål, Phera Stål, Propetes Walker, Pseudophera Melichar e Cleusina Cavichioli \& Sakakibara, apresentam o metepímero com uma projeção angular, onde as tégminas se encaixam quando em repouso (Young 1968; CAVichioli \& SaKaKibara 1989). Mejdalani (2000) propôs um novo grupo de gêneros [Cleusiana] com base em sua análise filogenética dos gêneros de Proconiini com mero exposto. Neste estudo, Oncometopia é grupo-irmão de Hyogonia, e Homalodisca seria parafilético.
O edeago das espécies de Oncometopia pode variar inter- e intra-especificamente (YouNG 1968). Em O. facialis, pode haver uma variação na posição e no tamanho dos espinhos do edeago (SCHRÖDER 1959; EMMrich 1975). O gênero Oncometopia é muito relacionado a Homalodisca, que também ocorre em citros, diferindo principalmente, pela fronte bastante convexa (YounG 1968).

Exemplares de $O$. facialis localizam-se e realizam sua alimentação em ramos mais desenvolvidos, mas não completamente lenhosos. Dificilmente ocorrem em ramos novos com brotações recentes e são mais facilmente encontrados em ramos eretos. Fêmeas dessa espécie, no período de oviposição, apresentam duas manchas esféricas, brancas e convexas sobre as asas anteriores, como observado também em fêmeas de Homalodisca ignorata Melichar. Os ovos são depositados, lado a lado, sob a epiderme da folha em uma única camada e recobertos por uma substância branca. Predominantemente, a sua postura localiza-se na face inferior da folha, em grupos de 4 a 21 ovos dispostos, lado a lado, em uma fileira levemente arqueada e cobertos por uma fina camada de epiderme. A fase jovem dura, em média, 76 dias, sob temperatura flutuante (Almeida \& Lopes 1999).

\section{CICADELLINI}

\section{Bucephalogonia xanthophis (Berg, 1879)}

(Figs. 8A-8I)

Tettigonia xanthophis Berg,1879: 249.

Bucephalogonia xanthophis; Young, 1977: 1094.

Diagnose. Coloração geral muito variável, do verde até um verde-violáceo, podendo apresentar, ou não, conspícuas manchas escuras na coroa. Edeago pequeno, simétrico, curvado para cima na metade apical.

Cabeça. Moderadamente protuberante; com uma variação de cor muito grande (desde manchas conspícuas pretas até ausência de manchas); coroa com a margem anterior arredondada em vista dorsal; ocelos sobre a linha imaginária que tangencia os ângulos oculares anteriores e muito mais próximos dos olhos do que da linha mediana da coroa (Fig. 8A e 8B); coroa convexa, com uma série de pontuações; sutura frontogenal estendendo-se para a coroa e atingindo os ocelos; fronte convexa; impressões musculares distintas; face sem pubescência.

Tórax. Pronoto mais estreito do que a largura transocular, não-rugoso. Asas anteriores com área membranosa ocupando o terço apical, desde a altura do ápice do clavo, a área translúcida ou opaca pontuada (pigmentada de verde); veias distintas (Fig. 8C). Asas posteriores com a célula apical externa alargada e quase tocando a margem costal; veia $\mathrm{R}_{2+3}$ ausente (Fig. 8D). Pernas posteriores com fórmula setal 2.1.0; comprimento do basitarso aproxidamente igual à soma dos dois distais, com duas fileiras paralelas de cerdas na superfície plantar. Abdome do macho com um par de pequenos apódemas do esclerito III (Fig. 8F). 

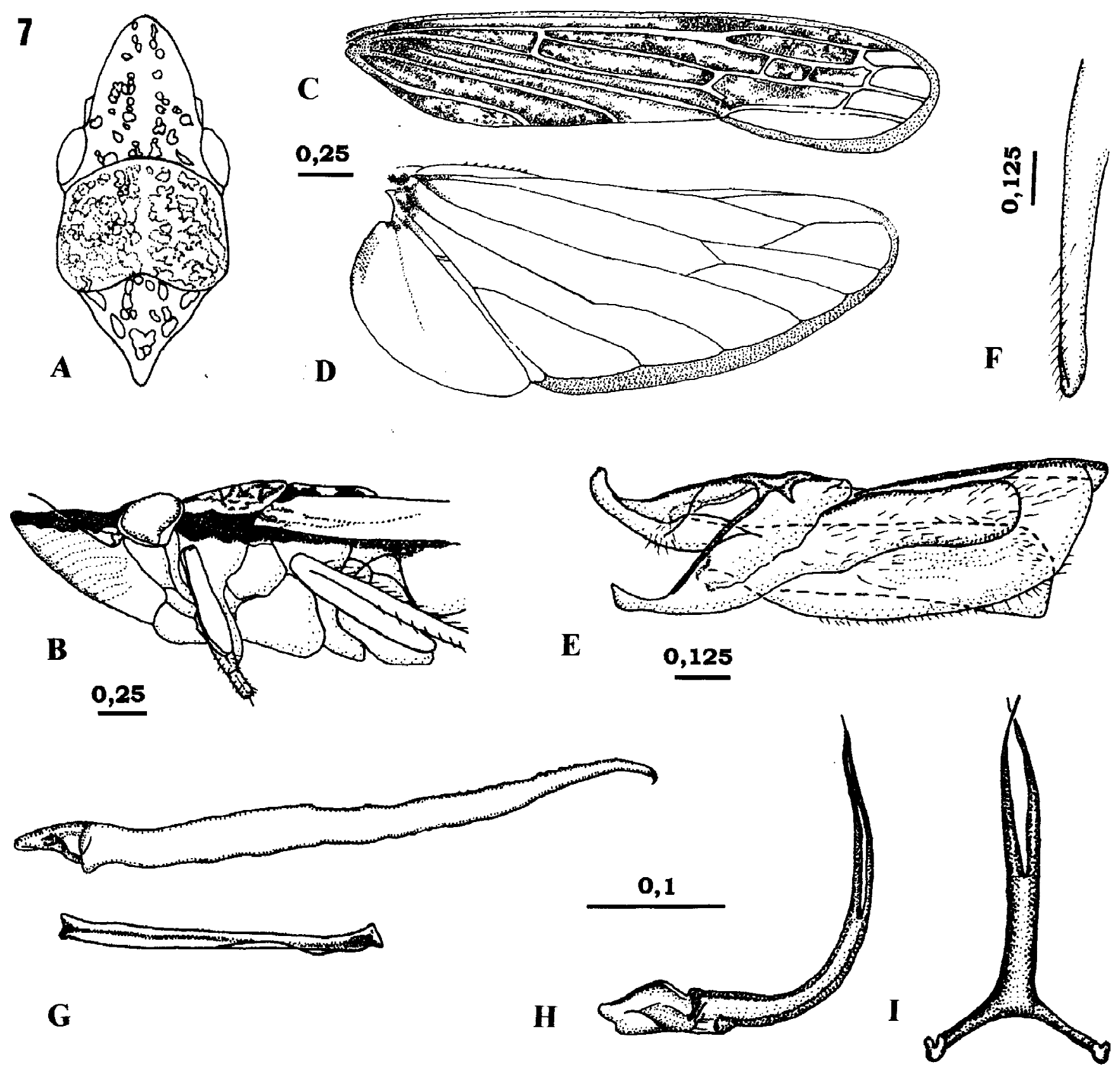

Fig. 7. Acrogonia citrina Marucci \& Cavichioli, sp. nov.: A e B, cabeça, pronoto e escutelo (vista dorsal e lateral); C, asa anterior; D, asa posterior; E, pigóforo (vista lateral); F, placa subgenital; G, conetivo e estilo (vista dorsal); H, edeago (vista lateral); I, edeago (vista ventral).

Genitália do macho. Pigóforo truncado no ápice. Placas subgenitais alargadas na base, afilando-se abruptamente antes da porção mediana, com os ápices estreitos e triangulares, estendendo-se além do ápice do pigóforo (Fig. 8E). Estilos sem lobo apical, estendendo-se além do ápice do conetivo; conetivo em T (Fig. 8G); edeago simétrico, muito pequeno, curvado para cima na metade apical, haste estreita apicalmente em vista ventral, margem reta na base e convexa no comprimento (Fig. $8 \mathrm{H} \mathrm{e} 8 \mathrm{I}$ ); paráfises e processos ausentes.

Comprimento. Machos: 4,75 mm $\pm 0,16(4,5-5,0 \mathrm{~mm})$. Fêmeas: $5,13 \mathrm{~mm} \pm 0,15(4,75-5,25 \mathrm{~mm})$.
Comentários. A coloração geral de B. xanthophisé amarela, com a área opaca das asas e algumas áreas do pronoto, esverdeadas. A perda de cor é muito comum nesta espécie e foi observada nos espécimens estudados por OsBorn (1926). Pode ser encontrada em plantas novas de citros ou em replantas dentro do talhão. Pode ser, também, coletada sobre a vegetação invasora do pomar em proporções semelhantes às da planta cítrica. Sua frequiência em viveiros é mais acentudada que a das outras espécies vetoras (PAIVA et al. 1996). Assemelha-se externamente a Scopogonalia subolivacea (Stål, 1862), também coletada em pomares cítricos, porém são distintas por 
apresentar o corpo mais robusto e a cabeça mais protuberante.

Dilobopterus costalimai Young, 1977

(Figs. 9A-9H)

Dilobopterus costalimai Young, 1977: 136.

Diagnose. Coloração amarela ou alaranjada, com uma série de manchas pretas formando desenhos característicos na cabeça, pronoto e escutelo; asas posteriores com o lobo jugal alargado; paráfise assimétrica.

Cabeça. Coloração variando de amarela a alaranjada, com uma mancha preta na margem anterior e outra, transversal, na frente dos ocelos, interligada com a primeira por duas pequenas manchas e com a margem posterior com três pequenas faixas longitudinais, duas na altura dos ocelos e uma mediana (Fig. 9A); face convexa, de cor amarela e com uma pequena mancha mediana preta na base da fronte.

Tórax. Coloração do pronoto variando de amarela a alaranjada com faixas laterais pretas, sinuosas; margem anterior com duas faixas pretas e no terço posterior com uma, em forma de W (Fig. 9A). Escutelo com uma grande mancha mediana preta em forma de $\mathrm{Y}$ e saindo de cada lado do braço do Y para a margem lateral adjacente, uma pequena mancha preta $\mathrm{e}$ estreita. Asas anteriores com a margem costal alargada, ocasionalmente com manchas foscas no ápice e nas células anteapicais; com uma ampla área membranosa distal; veias do clavo indistintas (Fig. 9B). Asas posteriores com um conspícuo lobo jugal alargado, parcialmente separado do resto da asa e estendendo-se além do ápice do clavo das asas anteriores, quando em posição de repouso (Fig. 9C). Pernas posteriores com basitarso muito mais longo que a soma do comprimento dos distais.

Genitália do macho. Pigóforo com numerosas macrocerdas irregularmente dispostas, com dois pequenos processos apicais em vista dorsal (Fig. 9D). Placa subgenital pequena, triangular, gradualmente estreitada, com o ápice arredondado; macrocerdas multiseriadas em quase toda a sua extensão (Fig. 9E). Estilos estendendo-se além do ápice do conetivo, com um distinto lobo pré-apical; conetivo pequeno, em forma de Y, com os braços fortemente divergentes (Fig. 9F). Edeago com um pequeno lobo estendendo-se posteriormente, arredondado apicalmente (Fig. 9G); paráfise assimétrica (não pareada) consistindo de um fino ramo alargado próximo à base, podendo apresentar o ápice denteado (Fig. 9H).

Comprimento. Machos: 8,15 mm 0,34 (7,5-8,5 mm). Fêmeas: $8,95 \mathrm{~mm} \pm 0,16(8,5-9,0 \mathrm{~mm})$.

Comentários. Esta espécie é bem característica, diferindo das demais espécies de Dilobopterus pelo aspecto geral, principalmente, o de coloração. Os ovos são colocados nas folhas novas, isoladamente, sob a epiderme, ao longo das nervuras, principalmente a central (PAIVA et al. 1996). A eclosão da ninfa dá-se por uma das extremidades do ovo, caracterizada pelo opérculo. Passa por cinco ínstares antes de atingir a fase adulta, com duração média de 65 dias à temperatura flutuante

(Almeida \& Lopes 1999).

Ferrariana trivittata (Signoret, 1854)

(10A-10F)

Tettigonia trivittata Signoret, 1854: 349.

Ferrariana trivittata; Young, 1977:1032.

Diagnose. Asas anteriores ornadas com três faixas longitudinais de cores contrastantes (laranja ou vermelho e azul); faixa de cor laranja ou vermelha na coroa, não ocupando completamente a margem anterior da cabeça; edeago curto, com a haste tão longa quanto os apódemas.

Cabeça. Moderadamente dilatada, com margem anterior arredondada em vista dorsal (Fig. 10A); ocelos localizados próximos da linha imaginária que tangencia os ângulos oculares anteriores, numa área ligeiramente côncava, mais próximos dos olhos do que da linha mediana da coroa; coroa com uma faixa laranja ou vermelha na margem anterior, levemente curvada a cada lado do ápice, deixando uma pequena área marginal ânterolateral, não coberta pela faixa; não pubescente; sutura lateral da fronte estendendo-se para a coroa e atingindo os ocelos; lóbulos suprantenais não protuberantes em vista dorsal; impressões musculares distintas; fronte convexa e medianamente achatada.

Tórax. Pronoto com largura igual à largura da cabeça; margem anterior do disco com uma faixa de cor laranja; ausência de pubescência. Asas anteriores com três faixas longitudinais de cores contrastantes (laranja ou vermelho e azul) e uma porção membranosa, descolorida, incluindo todas as células apicais; venação indistinta ou obscura no restante da asa, com leves pontuações (Fig. 10B). Pernas posteriores com fórmula setal dos fêmures 2.1.1; comprimento do basitarso superior à soma dos distais, com duas fileiras paralelas de cerdas na superfície plantar.

Genitália do macho. Pigóforo produzido posteriormente, afilado no ápice; com macrocerdas na metade apical; placa subgenital fina no ápice, não se estendendo além do ápice do pigóforo, com macrocerdas unisseriadas (Fig. 10C); estilos truncados no ápice e não se estendendo além do ápice do conetivo; conetivo em T, com a haste muito mais longa que os braços (Fig. 10E); edeago com haste reta (Fig. 10F) e apódemas tão longos quanto a haste, estendendo-se posteriormente; ausência de processos; paráfises com dois ramos simétricos (Fig. 10D).

Comprimento. Machos: 7,57 mm \pm 0,45 (6,8-8,0 mm). Fêmeas: $8,16 \mathrm{~mm} \pm 0,18(8,0-8,6 \mathrm{~mm})$.

Comentários. Espécie muito colorida e vistosa. A presença de uma faixa vermelha ou alaranjada na coroa e as três nas asas anteriores são caracteres distintivos em relação aos outros gêneros de Cicadellini (Young 1977). Pode ser coletada com armadilha luminosa (GRAVENA et al. 1997).

Hortensia similis (Walker, 1851)

(Figs. 11A-11E) 

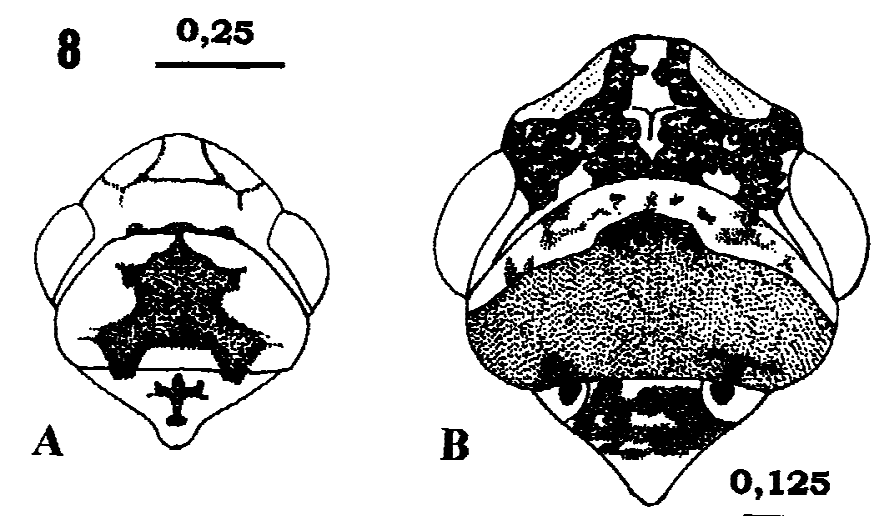

C
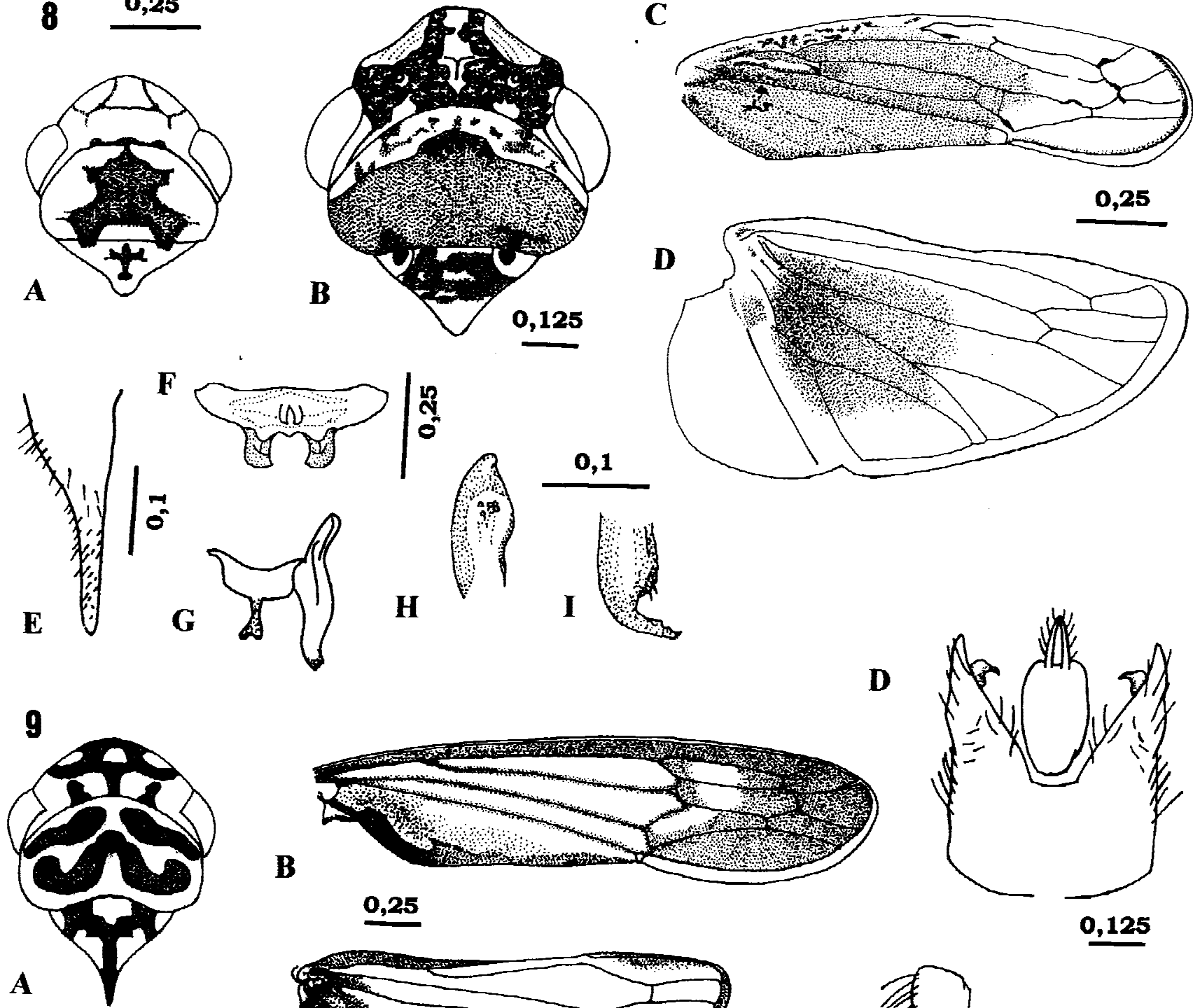

B

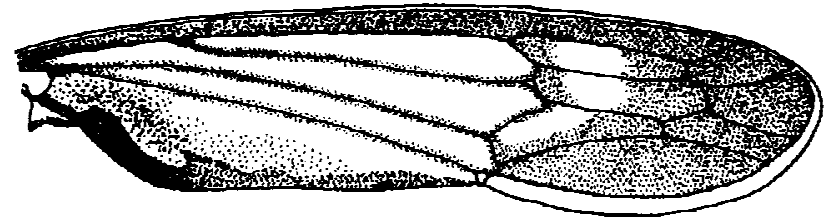

\section{0,25}

D

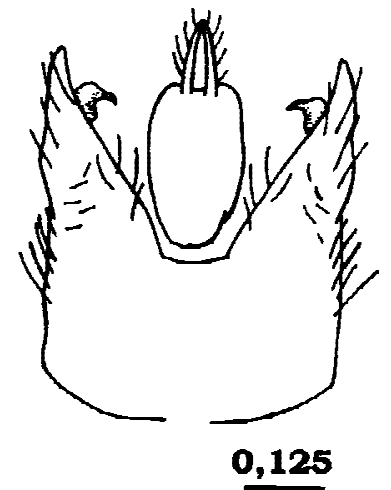

C
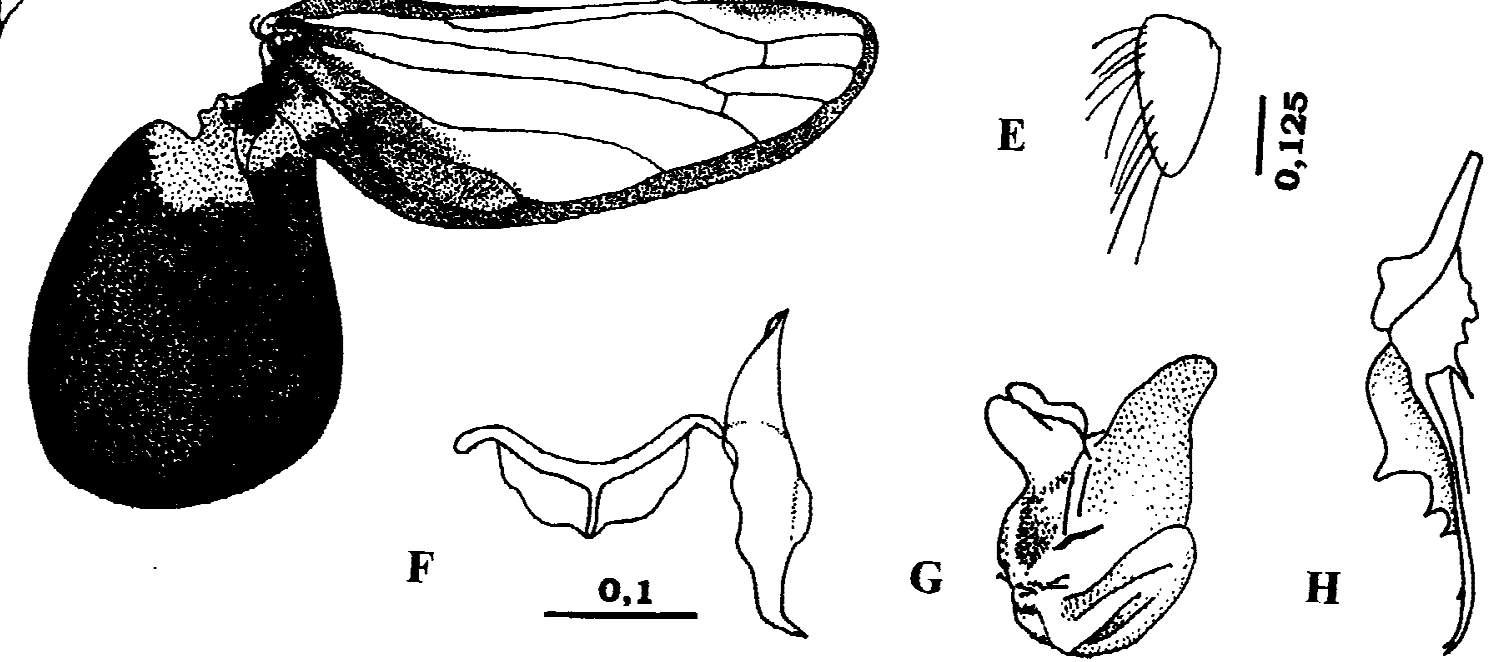

Fig. 8. Bucephalogonia xanthophis (Berg, 1879): A e B, cabeça, pronoto e escutelo (vista dorsal); C, asa anterior; D, asa posterior; E, placa subgenital (vista ventral); F, apódemas abdominais basais do macho; G, conetivo e estilo (vista dorsal); H, edeago (vista ventral); I, edeago (vista lateral). Fig. 9. Dilobopterus costalimai Young, 1977: A, cabeça, pronoto e escutelo (vista dorsal); B, asa anterior; C, asa posterior; D, pigóforo (vista dorsal); E, placa subgenital (vista ventral); F, conetivo e estilo (vista dorsal); G, edeago (vista lateral); H, paráfise (vista dorsal). 
Tettigonia similis Walker, 1851:

Hortensia similis; Young, 1977: 807.

Diagnose. Cabeça, margem anterior do pronoto e escutelo verde-claros; coroa com uma série de manchas lineares pretas próximas aos ocelos; haste do edeago não abruptamente alargada no ápice.

Cabeça. Margem anterior arredondada em vista dorsal (Fig. 11A); ocelos localizados próximos à linha imaginária que tangencia os ângulos oculares anteriores, cada um localizado mais próximo do olho do que da linha mediana; coroa convexa, com um padrão de manchas lineares escuras próximas aos ocelos; sutura frontogenal estendendo-se sobre a coroa e atingindo os ocelos; impressões musculares distintas.

Tórax. Pronoto com a largura menor ou igual à largura da cabeça; disco levemente rugoso transversalmente (estrias na porção posterior) e a porção anterior com manchas lineares pretas; não pubescente. Asas anteriores com uma área opaca, esverdeada, delimitada por uma membrana incluindo todas as células apicais; venação indistinta ou obscura, com pontuações, e ultrapassando o ápice do ovipositor quando em posição de repouso. Pernas posteriores com fómula setal 2.1.1; basitarso mais longo que a soma do comprimento dos distais e com duas fileiras paralelas de cerdas na superfície plantar.

Genitália do macho. Pigóforo largo, estreitando-se na margem dorsoapical; com poucas macrocerdas no ápice. Placa subgenital triangular, estreita e pontiaguda no ápice, estendendo-se além do ápice do pigóforo, margem com macrocerdas unisseriadas (Fig. 11B). Estilo robusto basalmente e com ápice unciforme e estendendo-se além do ápice do conetivo. Conetivo na forma de T, com os braços amplamente divergentes (Fig. 11C). Edeago simples, pequeno, em vista lateral com a haste não abruptamente alargada no ápice (Fig. 11D e $11 \mathrm{E})$, paráfises e processos ausentes.

Comprimento. Machos: 6,2 mm $\pm 0,35$ (6,0-7,0 mm) Fêmeas: $6,77 \mathrm{~mm} \pm 0,51(5,5-7,0 \mathrm{~mm})$.

Comentários. Esta espécie apresenta uma ampla distribuição, desde o sul da Argentina até o Norte do Brasil. O estudo do material do DZUP revelou esta distribuição e uma variação de cor, principalmente na região da cabeça, porém sem haver alterações estruturais, com uma leve variação intra-específica na forma do edeago. Espécie extremamente abundante que se alimenta primariamente de gramíneas (WILSON \& CLARIDGE 1991).

Hortensia Metcalf \& Bruner é similar em muitos aspectos à Kapateira Young, principalmente as fêmeas, mas difere pelo porte menor, pelo pigóforo do macho dilatado, com o conetivo em $\mathrm{Y}$ e o edeago muito menor quando comparado ao longo edeago de Kapateira (Young 1977).

Macugonalia cavifrons (Stål, 1862)

(Figs. 12A-12D)

Tettigonia cavifrons Stål, 1862:41.

Macugonalia cavifrons; Young, 1977:944.

Diagnose. Disco da coroa, pronoto e asas anteriores com o mesmo padrão de coloração, formado por pequenas máculas amareladas sobre um verde-escuro; face com muitas manchas escuras no disco da fronte e somente uma área amarelada central imaculada.

Cabeça. Dorsalmente, levemente dilatada, com a margem anterior alargada (Fig. 12A); ocelos localizados sobre ou levemente atrás da linha imaginária que tangencia os ângulos oculares anteriores, cada um situado mais próximo do olho do que da linha mediana da coroa; sutura frontogenal estendendose sobre a coroa e atingindo os ocelos; impressões musculares não muito distintas; fronte convexa e achatada medianamente; face com manchas escuras, principalmente na fronte, restando somente uma área mediana amarelada; coroa verde-escura com várias pequenas máculas amareladas.

Tórax. Pronoto com largura menor que a largura da cabeça e com o mesmo padrão de manchas da coroa. Asas anteriores com o mesmo padrão de cor da coroa e pronoto, porém com a extremidade membranosa escurecida, veias indistintas ou obscuras (Fig. 12B). Pernas posteriores com fórmula setal do fêmur 2.1.1; comprimento do basitarso maior que a soma do comprimento dos distais e com duas fileiras paralelas de cerdas na superfície plantar.

Genitália do macho. Pigóforo dilatado posteriormente, afilado no ápice; com macrocerdas localizadas mais próximas do ápice. Placa subgenital muito pequena, triangular não se estendendo além do terço basal do pigóforo. Estilos estendendo-se além do ápice do conetivo e com um lobo lateral próximo à metade do comprimento. Conetivo em Y com os braços amplamente divergentes (Fig. 12C). Edeago convexo em vista dorsal, com um par de finos processos iniciando-se na base (vista ventral) e estendendo-se posteriormente ao ápice do edeago (Fig. 12D); paráfises ausentes.

Comprimento. Machos: 7,8 mm $\pm 0,35$ (7,1-8,1 mm). Fêmeas: $8,21 \mathrm{~mm} \pm 0,35(7,9-9,0 \mathrm{~mm})$.

Comentários. De modo geral, as espécies pertencentes ao gênero Macugonalia são identificadas por caracteres externos, já que as genitálias dos machos são pouco variáveis e as das fêmeas são muito similares na maioria das espécies. Essa espécie é muito variável no tamanho; possui manchas e pontuações leves em uma pequena área da coroa, pronoto, escutelo e fronte (Young 1977). M. cavifrons é semelhante a M. sobrina (Stål, 1862), sendo que nesta última o VII esternito é mais curto. É uma espécie presente nas áreas de floresta hidrofólia e de cerrado, próximas ao pomar de citros, porém ocorre também em citros, na cana-de-açúcar, no cafeeiro e em floresta semidecidual aluvial, em menor proporção.

Macugonalia leucomelas (Walker, 1851)

(Figs. 13A-13D)

Tettigonia leucomelas Walker, 1851:764.

Macugonalia leucomelas; Young, 1977:944.

Diagnose. Asas anteriores escuras com duas manchas largas de cor marfim. Coloração geral preta com algumas 


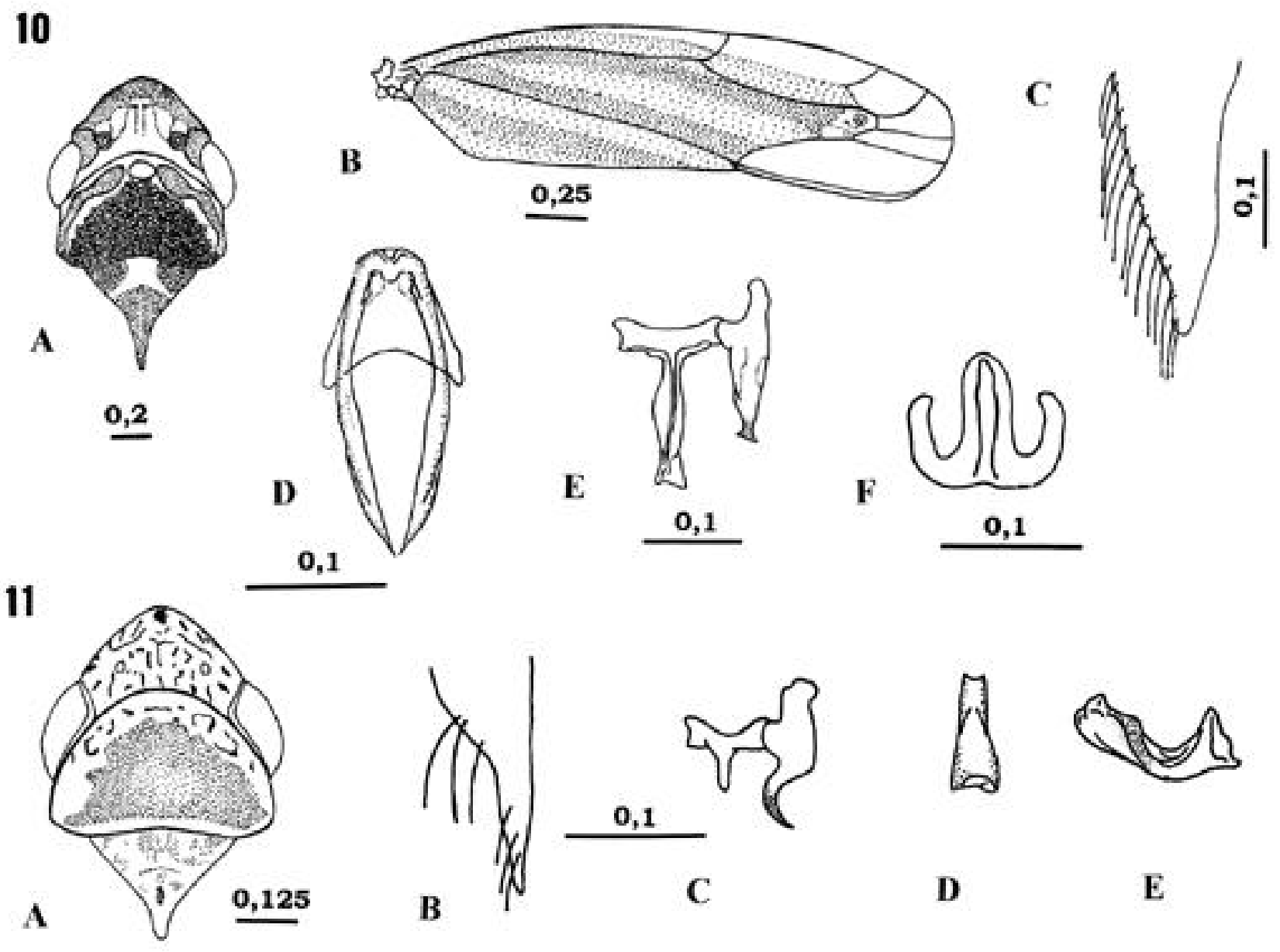

Fig. 10. Ferrariana trivittata (Signoret, 1854): A, cabeça, pronoto e escutelo (vista dorsal); B, asa anterior; C, placa subgenital (vista ventral); D, paráfises (vista ventral); E, conetivo e estilo (vista dorsal); F, edeago (vista ventral). Fig.11. Hortensia similis (Walker, 1851): A, cabeça, pronoto e escutelo (vista dorsal); B, placa subgenital (vista dorsal); C, conetivo e estilo (vista dorsal); D, edeago (vista ventral); E, edeago (vista lateral).

pequenas manchas claras.

Cabeça. Levemente dilatada com a margem anterior arredondada, em vista dorsal; de coloração preta mosqueada de branco (Fig. 13A ), em alguns espécimens, totalmente preta com duas faixas transversais, brancas ou marfim, na altura dos ocelos; ocelos localizados levemente à frente da linha imaginária que tangencia os ângulos oculares anteriores, cada um situado mais próximo do olho do que da linha mediana da coroa; sutura frontogenal estendendo-se sobre a coroa e atingindo os ocelos; lóbulos suprantenais não-protuberantes em vista dorsal; impressões musculares não muito distintas.

Tórax. Pronoto, na maior largura, menor do que a largura transocular; pronoto com bordas pálidas nas margens laterais e a posterior, variavelmente marcada de branco; porção anterior do pronoto e escutelo de coloração escura com manchas amarelas; disco do pronoto podendo apresentar, em alguns espécimens, várias pequenas manchas brancas ou marfim. Asas anteriores seguindo o mesmo padrão de coloração e de manchas do pronoto, porém com duas manchas largas distintas, brancas ou marfim, uma no terço basal, a outra na altura do ápice do clavo, com veias indistintas ou obscuras (Fig. 13B). Pernas posteriores com fórmula setal dos fêmures 2.1.1; comprimento do basitarso maior que a soma do comprimento dos distais, com duas fileiras paralelas de cerdas na superfície plantar.

Genitália do macho. Pigóforo dilatado posteriormente, alargado no ápice, com grupos de macrocerdas localizadas no ápice posterior e estendendo-se sobre as margens ventrais. Placa subgenital pequena, triangular, não se estendendo além do terço basal do pigóforo. Estilos estendendo-se além do ápice do conetivo; conetivo em Y com os braços amplamente divergentes (Fig. 13C). Edeago pequeno, convexo em vista dorsal, com um par de finos e longos processos iniciando-se na base (vista ventral) e estendendo-se posteriormente ao ápice do edeago (Fig. 13D); paráfises ausentes.

Comprimento. Machos: 5,29 $\mathrm{mm} \pm$ 0,26 (4,7-5,65 mm). Fêmeas: 5,82 mm $\pm 0,16(5,6-6,1 \mathrm{~mm})$.

Comentários. É a espécie mais comum encontrada em coleções (Young 1977). Signoret (1853) verificou que essa espécie é extremamente variável; as manchas claras nas asas 

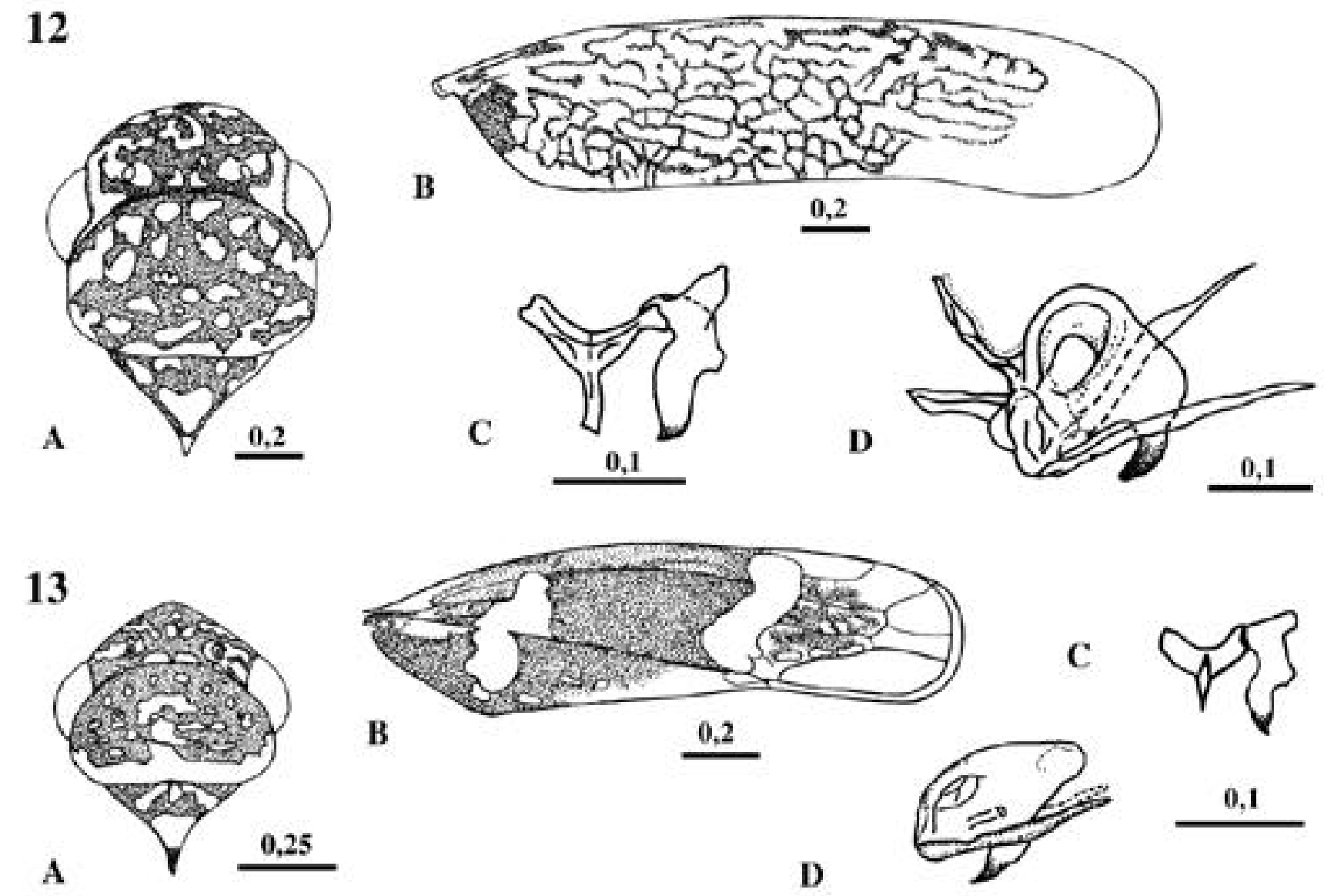

Fig. 12. Macugonalia cavifrons (Stal, 1862): A, cabeça, protonoto e escutelo (vista dorsal); B, asa anterior; C, conetivo e estilo (vista dorsal); D, edeago (vista lateral). Fig. 13. Macugonalia leucomelas (Walker, 1851): A, cabeça, pronoto e escutelo (vista dorsal); B, asa anterior; C, conetivo e estilo (vista dorsal); D, edeago (vista lateral).

anteriores podem ser menores, as veias mosqueadas de amarelo e as asas, em alguns espécimens, podem ser mais escuras; face quase sempre preta.

\section{Plesiommata corniculata Young, 1977}

(Figs. 15A-15F)

Plesiommata corniculata Young, 1977:601.

Diagnose. Cabeça com uma mancha preta de forma variável entre a porção mediana da coroa e o ápice; edeago pequeno e bastante expandido no ápice, em vista lateral.

Cabeça. Coloração amarelo-pálida; uma estreita borda ou círculo preto ao redor de cada ocelo e uma mancha da mesma cor entre a área mediana da coroa e o ápice (Fig. 15A); coroa com o ápice arredondado em vista dorsal; face irregularmente mesclada com áreas marrom-claras e escuras nas laterais, com uma área mediana mais clara; impressões musculares distintas.

Tórax. Pronoto na maior largura, menor que a largura transocular, com duas faixas transversais amarronzadas (variável intraespecificamente). Asas anteriores hialinas, com veias longitudinais marrons, salientes, com duas das três células anteapicais abertas e pelo menos duas células apicais falsamente abertas na base (ausência de pigmentação) (Fig. 15B). Pernas posteriores com fórmula setal do fêmur 2.1.1; comprimento do basitarso maior ou igual à soma do comprimento dos distais e com duas fileiras paralelas de cerdas na superfície plantar.

Genitália do macho. Placa subgenital gradualmente cônica na metade basal, afinando-se na metade apical (Fig. 15C). Conetivo em Y, com os braços mais curtos do que a haste, estilos estendendo-se posteriormente ao ápice do conetivo e apresentando nitidamente um lobo pré-apical (Fig. 15D). Edeago pequeno, expandido no ápice (Fig. 15F), em vista ventral semelhante a uma taça (Fig. 15E); processos do edeago (1 par) iniciando-se ventralmente na base e estendendo-se dorsalmente sobre a haste; paráfises ausentes.

Comprimento. Machos: 3,99 mm $\pm 0,12(3,8-4,15 \mathrm{~mm})$.

Comentários. Segundo Gravena et al. (1997), esta é a espécie 

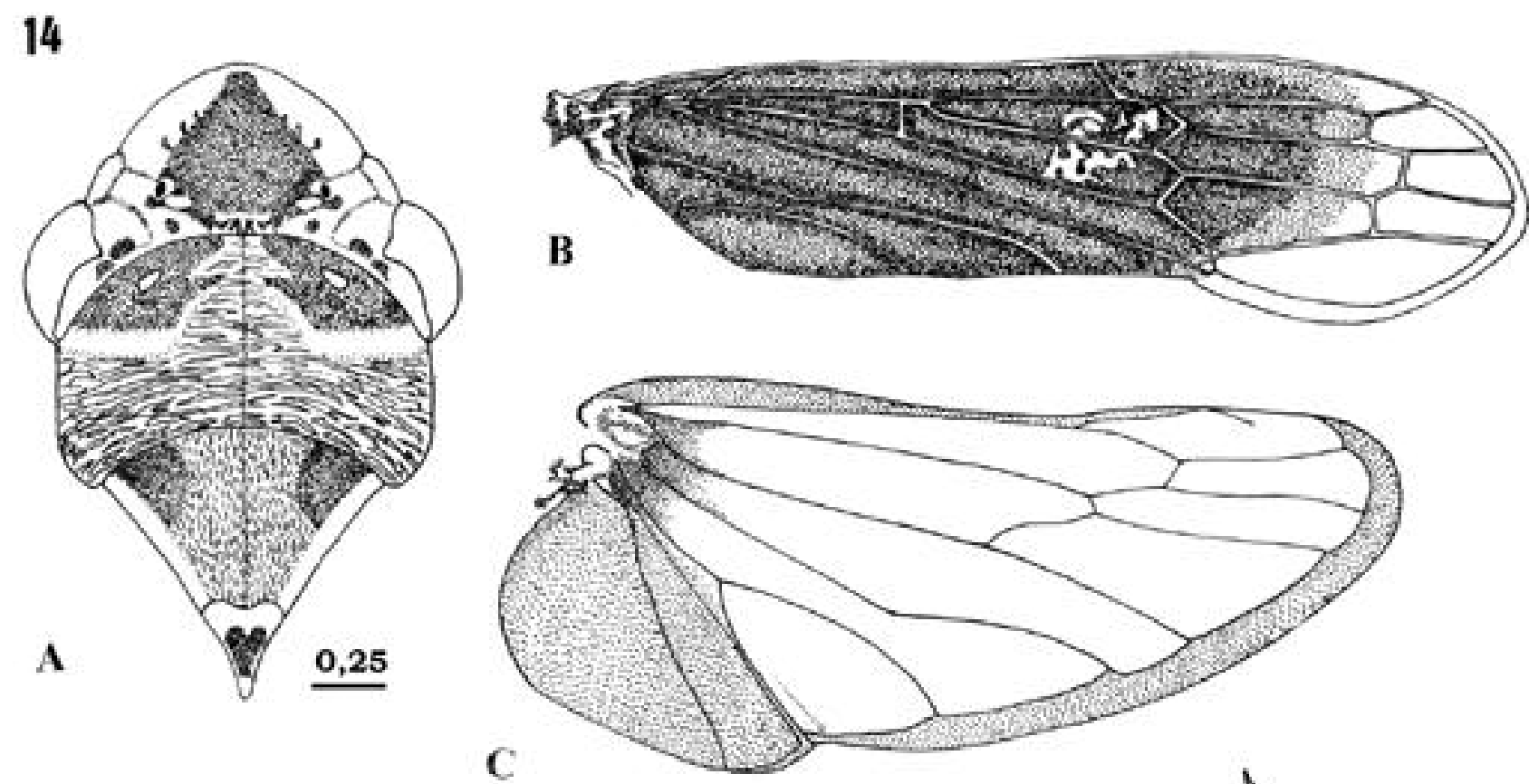

C

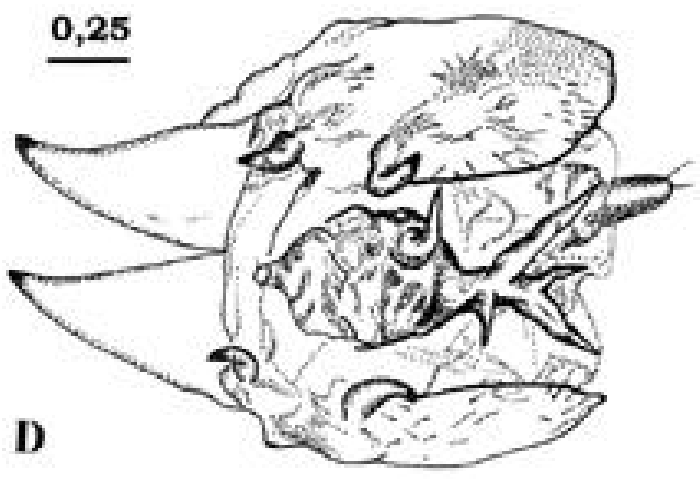

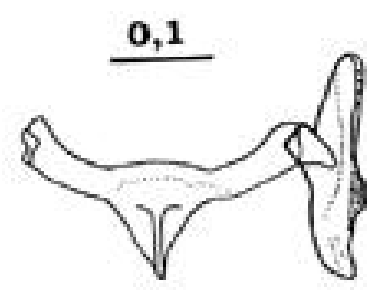

E

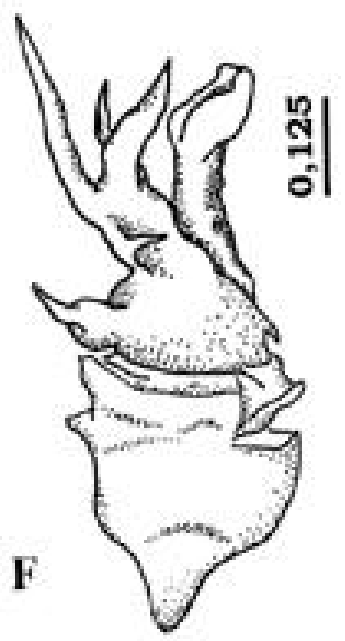

Fig. 14. Oncometopia facialis (Signoret, 1854): A, cabeça, pronoto e escutelo (vista dorsal); B, asa anterior; C, asa posterior; D, pigóforo e edeago (vista ventral); E, conetivo e estilo (vista dorsal); F, edeago (vista lateral).

mais facilmente encontrada em gramíneas, raramente nas plantas cítricas. Nos levantamentos, $P$. cornniculata foi coletada nas plantas invasoras dos pomares, principalmente gramíneas (grama-seda e capim braquiária).

\section{Plesiommata mollicella (Fowler, 1900)} (Figs. 16A-16C)

Tettigonia mollicella Fowler, 1900:289. Plesiommata mollicela; Young, 1977:596.

Diagnose. Edeago, em vista lateral, com uma expansão dorso-lateral ao longo de seu comprimento.

Cabeça. Coloração amarelo-pálida com uma mancha preta de forma variável entre a área mediana da coroa e o ápice; uma série de manchas marrom-escuras dispostas desordenadamente em vista dorsal (variação intraespecífica); margem anterior arredondada (Fig. 16A). Demais características semelhantes às de $P$. corniculata.

Genitália do macho. Semelhante à de $P$. corniculata, exceto o edeago, cuja haste, em vista lateral, apresenta uma expansão dorso-lateral (Figs. 16B e 16C).

Comprimento. Machos: 4,58 mm $\pm 0,24(5,0-4,25 \mathrm{~mm})$. Fêmea: $5,29 \mathrm{~mm} \pm 0,25(5,75-5,0 \mathrm{~mm})$.

Comentários. Foi coletada em um número bem maior que $P$. corniculata, na vegetação espontânea do pomar e em gramíneas, predominantemente. 


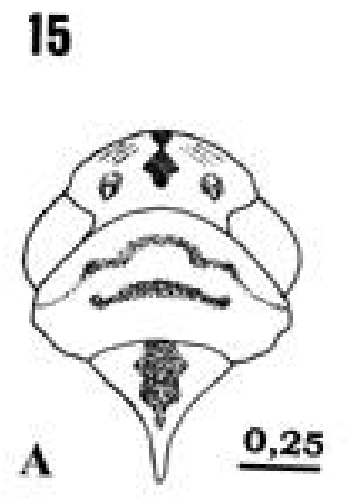

D

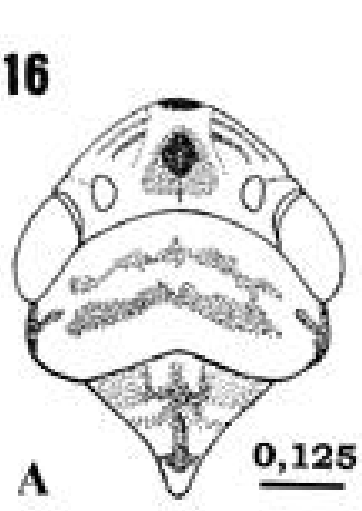

B

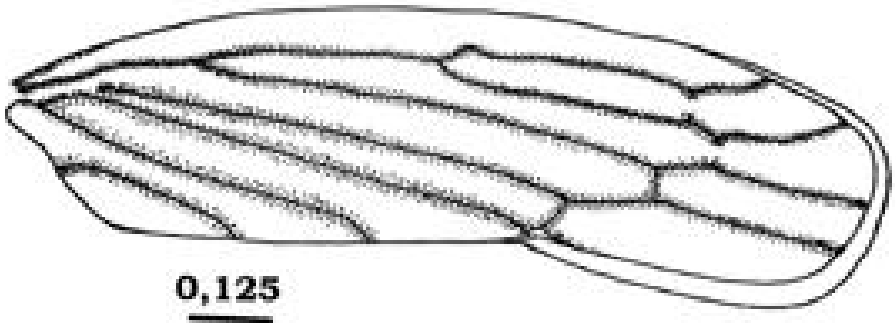

C

\section{0,1}

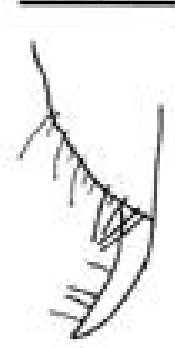

$\mathbf{E}$

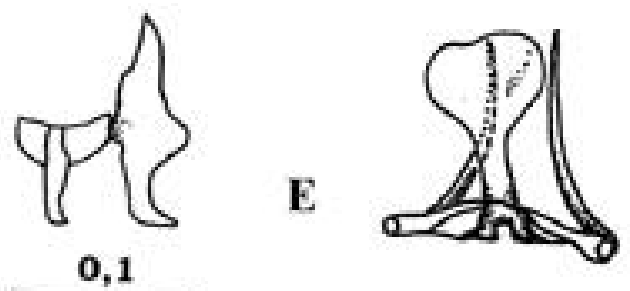

B

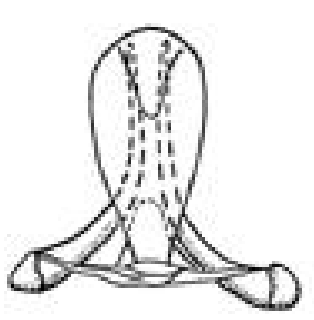

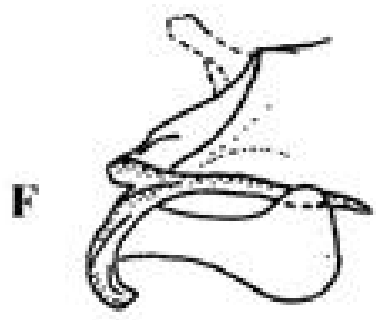

0,1

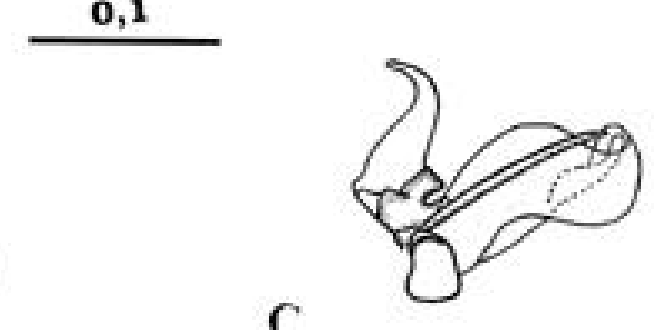

C

Fig. 15. Plesiommata corniculata Young, 1977: A, cabeça, pronoto e escutelo (vista dorsal); B, asa anterior; C, placa subgenital (vista ventral); D, conetivo e estilo (vista dorsal); E, edeago (vista ventral); F, edeago (vista lateral). Fig. 16. Plesiommata mollicella (Fowler, 1900): A, cabeça, pronoto e escutelo (vista dorsal); B, edeago (vista ventral); C, edeago (vista lateral.

Agradecimentos. Gostaríamos de agradecer à Dra. Teresinha Augusta Giustolin e ao Prof. Dr. João Roberto Spotti Lopes por cederem as amostras de cigarrinhas, tornando possível esse trabalho; a Patrícia Milano pelos desenhos; à CAPES pela concessão da bolsa de mestrado ao primeiro autor e ao Fundo Paulista de Defesa da Citricultura (FUNDECITRUS) pelo apoio financeiro.

\section{REFERÊNCIAS}

AlmeidA, R. P. P. \& J. R. S. L. Lopes. 1999. Desenvolvimento de imaturos de Dilobopterus costalimai Young, Oncometopia facialis (Signoret) e Homalodisca ignorata Melichar (Hemiptera, Cicadellidae) em citros. Anais da Sociedade Entomológica do Brasil 28(1):179182.

Blocker, H. D. \& B. W. Triplehorn. 1985. External morphology of leafhoppers, p.41-60. In: L. R. Nault \& J. G. Rodriguez. (eds.). The leafhoppers and planthoppers. New York, John Wiley, 500p.

Cavichioli, R. R. \& A. M. SaKakibara. 1989. Novo gênero e espécie de Proconiini (Homoptera, Cicadellidae). Revista Brasileira de Zoologia 6(1): 171-174.

Cavichioli, R. R. \& K. M. R. Zanol. 1991. Espécies de Cicadellinae e Deltocephalinae (Homoptera, Cicadellinae) da Ilha de Maracá, Roraima. Acta Amazônica 21:55-61.
Claridge, M. F. 1985. Acoustic signals in the Homoptera: Behavior, Taxonomy, and evolution. Annual Review of Entomology 30:297317.

EmmRich, R. 1975. Zur Kenntnis der Gattung Oncometopia Stål, 1869 (Homoptera, Cicadelldae, Cicadelliane). Entomologishe Abhandlungen Staatliches Museum Für Tierkunde in Dresden 40(9):277-303.

Frazier, N. W. 1944. Phylogenetic relationship of the nine known leafhopper vectors of Pierce's disease of grape. Phytopathology 34:1000-1001.

Fundecitrus. 1999. Descobertos mais 6 vetores de CVC. Revista do Fundecitrus 94:8-9.

Gravena, S.; J. R. S. Lopes; P. E. B. Paiva; P. T. Yamamoto \& S. R. Roberto. 1997. Os vetores da Xylella fastidiosa, p. 37-53. In: L. C. Donadio \& C. S. Moreira (ed.). Clorose variegada dos citros. Bebedouro, Fundecitrus.

LOPES, J. R. S. 1996 Mecanismos de transmissão de Xylella fastidiosa por cigarrinhas. Laranja 17:79-92.

Lopes, J. R. S.; M. J. G. Beretta; R. Harakava; R. P. P. Almeida; R. KRÜgner \& A. JR. GARCIA. 1996. A. Confirmação da transmissão por cigarrinhas do agente causal da clorose variegada dos citros, Xylella fastidiosa. Fitopatologia Brasileira 21:343. Suplemento.

Marucci, R. C.; R. R. Cavichioli \& R. A. Zucchi. 1999. Chave para as espécies de cigarrinhas (Hemiptera: Cicadellidae: Cicadellinae) vetoras da clorose variegada dos citros (CVC). Anais da Sociedade 
Entomológica do Brasil 28(3): 439-446.

Marucci, R. C.; R. R. Cavichioli \& R. A. Zucchi. 2000. Descrição dos estádios imaturos de Acrogonia sp., Dilobopterus costalimai Young e Oncometopia facialis (Signoret) (Hemiptera: Cicadellidae: Cicadellinae). Anais da Sociedade Entomológica do Brasil 29(4): 667-681.

Mejdalani, G. 1998. Morfologia externa dos Cicadellinae (Homoptera: Cicadellidae): Comparação entre Versigonalia ruficauda (Walker) (Cicadellini) e Tretogonia cribrata Melichar (Proconiini), com notas sobre outras espécies e análise da terminologia. Revista Brasileira de Zoologia 15(2):451-544.

Mejdalani, G. 2000. Morfologia externa e análise cladística de Proconiini com o mero posterior exposto (Hemiptera, Cicadellidae, Cicadellinae). Tese de Doutorado. São Paulo, USP, $\mathrm{xiii}+221 \mathrm{p}$.

Metcalf, Z. P. 1965. General catalogue of the Homoptera, Cicadelloidea. Part I. Tettigellidae. Washington,USDA, Agricultural Researche Service, 730p.

Nielson, M. W. 1985. Leafhoppers systematics, p.11-39. In: L. R. NAULt \& J. R. Rodriguez (ed.). The leafhoppers and planthoppers. New York, John Wiley, 500p.

Osborn, H. 1926. Neotropical Homoptera of the Carnegie Museum. Part 5. Report upon the collections in the subfamily Cicadellinae, with descriptions of new species. Carnegie Museum Annals 16:155249.

Paiva, P. E. B.; J. L. Silva; S.Gravena \& P. T. Yamamoto. 1996. Cigarrinhas de xilema em pomares de laranja do Estado de São Paulo. Laranja 17(1):41-54.

Roberto, S. R.; A. Coutinho; J. E. O. Lima; V. S. Miranda \& E. F. Carlos. 1996. Transmissão de Xylella fastidiosa pelas cigarrinhas Dilobopterus costalimai, Acrogonia terminalis e Oncometopia facialis em citros. Fitopatologia Brasileira 21(4):517-518.

SCHRÖDER, H. 1959. Taxionomische und tiergeographische studien an neotropischen Zikaden (Cicadellidae, Tettigelinae). Der Senckenbergischen Naturforschenden Gesellschaft 499:193.

Signoret, V. 1853. Revue Iconographique des Tettigonides. Annales de la Societé Entomologique de France 1(3):349.

Wilson, M. R. \& M. F. Claridge. 1991. Nymphal Identification, p.121128. In: Handbook for identification of leafhoppers and planthoppers of rice. Wallingford, CAB International, Natural Resources Institute, 142p.

Yamamoto, P. T. \& S. Gravena. 2000. Espécies e abundância de cigarrinhas e psilídeos (Homoptera) em pomares cítricos. Anais da Sociedade Entomológica do Brasil 29(1):169-176.

Yamamoto, P. T.; S. R. Roberto; Dalla Pria JR, W.; M. R. Felippe; V. S. Miranda; D. C. Teixeira \& J. R. S. Lopes. 2000. Transmissão de Xylella fastidiosa pelas cigarrinhas Homalodisca ignorata, Acrogonia virescens e Molomea cincta (Hemiptera: Cicadellidae) em plantas cítricas. Summa Phytopathologica 26(1):284.

Young, D. A. 1968. Taxonomic study of the Cicadellinae (Homoptera: Cicadellidae). Part 1. Proconiini. United States National Museum Bulletin 261:1-287.

Young, D. A. 1977. Taxonomic study of the Cicadellinae (Homoptera: Cicadellidae). Part 2. New World Cicadelliini and genus Cicadella. North Carolina Agricultural Experiment Station Technical Bulletin 239:1-1135.

Young, D. A. 1986. Taxonomic study of the Cicadellinae (Homoptera: Cicadellidae). Part 3. Old World Cicadelliini. North Carolina Agricultural Experiment Station Technical Bulletin 281:1-639. 